Gut, 1979, 20, 121-125

\title{
Absorption of antigens after oral immunisation and the simultaneous induction of specific systemic tolerance
}

\author{
E. T. SWARBRICK ${ }^{1}$, C. R. STOKES, AND J. F. SOOTHILL \\ From the Department of Immunology, Institute of Child Health, London
}

SUMMARY Antigenic proteins may be absorbed intact. We report here results from in vivo experiments in mice showing that the prior feeding of protein antigen may reduce the subsequent absorption of that antigen without altering its elimination from the circulation. This may be a function of local immunity. We have also shown that the same feeding regime can paradoxically induce a state of systemic tolerance and suggest that the two phenomena contribute to the safe handling of these antigens.

Large molecular weight proteins are absorbed intact by the intestine in quantities which are insignificant nutritionally but potentially important immunologically (Walker and Isselbacher, 1974). There is some evidence from in vitro experiments in rats to suggest that animals which have previously eaten an antigen absorb less of it subsequently (Walker et al., 1972) and it has been suggested that this immune exclusion is a function of local antibody (Bazin et al., 1973).

In 1946 Chase showed that the prior ingestion of dinitrochorobenzene (DNCB) by rabbits reduces the subsequent sensitisation by that substance (Chase, 1946). Recent work has shown reduced antibody production to parenterally administered bovine serum albumin or sheep red blood cells when preceded by a period of antigen feeding (Thomas and Parrott, 1974; André et al., 1975). We have performed experiments to investigate the paradox that both local immunity, causing exclusion of antigen, and also specific systemic tolerance can result from the same antigenic experience-feeding.

\section{Methods}

ANIMALS AND EXPERIMENTAL TECHNIQUES Groups of $8 \mathrm{C}_{3} \mathrm{H}$ mice aged 2 to 3 months were used in all experiments and maintained on Oxoid diets

\footnotetext{
${ }^{1}$ Address for correspondence: E. T. Swarbrick, Department of Gastroenterology, St Bartholomew's Hospital, West Smithfield, London EC1A 7BE.
}

Received for publication 10 August 1978 which contain no egg protein. Twenty-five milligrams of ovalbumin (grade III, Sigma) dissolved in $0.2 \mathrm{ml}$ saline was administered daily for 14 days into the stomach of experimental animals through a Portex tube $1 \mathrm{~mm}$ in diameter. Control mice were given saline. The animals were then maintained on normal diet only for 14 days before study in one of three ways: (1) the absorption of ovalbumin; (2) the elimination of ovalbumin from the circulation; (3) the antibody response to parenteral immunisation with ovalbumin.

\section{RADIOLABELLING}

125I-ovalbumin was prepared by using a modification of the chloramine-T method (Hunter and Greenwood, 1962). Ten micrograms of ovalbumin (grade $\mathrm{V}$, Sigma) was iodinated with $1 \mathrm{mCi} \mathrm{Na}{ }^{125}$ I (Radiochemical Centre, Amersham) using $100 \mu \mathrm{g}$ chloramine $\mathrm{T}$ in $45 \mu \mathrm{l}$ phosphate buffer $\mathrm{pH} 7.4$ at room temperature. The reaction was stopped immediately after mixing by the addition of $240 \mu \mathrm{g}$ sodium metabisulphite in $100 \mu$ l of buffer. Excess iodide ( $20 \mu 11 \%$ sodium iodide) and 5 drops of $5 \%$ human serum albumin in buffer were added and the labelled, monomeric ovalbumin separated from free iodide and aggregated protein by gel filtration on a Sephadex $\mathrm{G} 150$ column $30 \mathrm{~cm}$ by $1 \mathrm{~cm}$.

RADIOIMMUNOASSAY (RIA)

Duplicate assay tubes (LP3 Luckham) were set up containing $50 \mu \mathrm{l}$ test serum, $50 \mu \mathrm{l}$ normal mouse serum, and $100 \mu \mathrm{l}{ }^{125} \mathrm{I}$-ovalbumin adjusted to give approximately $60000 \mathrm{cpm} 100 \mu \mathrm{l}$ rabbit anti- 
ovalbumin antiserum (Miles Laboratories (UK) Ltd) was added at a final dilution of 1 in 30000 which bound $30 \%$ of the labelled ovalbumin. After mixing and overnight incubation at room temperature $100 \mu$ l donkey anti-rabbit antiserum (Wellcome Reagents Ltd) (final dilution 1 in 120) and $100 \mu$ l normal rabbit serum (final dilution 1 in 1000) were added to precipitate any soluble immune complexes formed in the first stage. After overnight incubation at $4^{\circ} \mathrm{C}$, the precipitate containing the antibodybound labelled ovalbumin was separated by centrifugation (1200 $\mathrm{g}$ for 20 minutes) and the tubes were counted in a $\gamma$ counter (Pannax). The percentage binding of the total counts available was then calculated and the concentrations of ovalbumin were read from a standard curve. The non-specific binding was less than $3 \%$ and the sensitivity of the assay was $0.05 \mathrm{ng} . \mathrm{ml}^{-1}$.

\section{HAEMAGGLUTINATION ASSAY}

Sheep red blood cells (SRBC) were coated with protein using chromic chloride. Heparinised SRBC were washed three times in normal saline at room temperature and spun down at $300 \mathrm{~g}$ for 10 minutes. One hundred microlitres of packed cells were mixed with $0.7 \mathrm{ml}$ normal saline and $100 \mu \mathrm{l}$ protein solution (ovalbumin $15 \mathrm{mg} \mathrm{ml}^{-1}$ in saline or human serum albumin (HSA) $1 \mathrm{mg} \mathrm{ml}^{-1}$ ). One millilitre of $0.01 \%$ chromic chloride in saline at $\mathrm{pH} 5$ was added drop by drop with continuous agitation. The final mixture was allowed to stand for 10 minutes and the reaction was stopped by adding phosphate buffered saline (PBS) pH 7.2. The coated cells were washed twice in $20 \mathrm{ml}$ PBS and resuspended to make a $1 \%$ solution.

Test sera were incubated in a water bath at $57^{\circ} \mathrm{C}$ for 30 minutes to inactivate complement, absorbed for one hour at room temperature with $10 \%$ uncoated SRBC to remove heterophile antibodies, and then spun at $500 \mathrm{~g}$ for 10 minutes. One hundred microlitres of adsorbed sera was doubly diluted twenty-four times in V-bottomed microtitre plates (Titertek) and $100 \mu 11 \%$ coated SRBC added to each well with negative and positive control sera being used in each experiment. The plates were allowed to settle for 90 minutes at room temperature and the end point of the reaction was taken as the last dilution of serum to show complete agglutination. The tests were performed in duplicate both with and without $50 \mu \mathrm{l}$ of $0 \cdot 1 \mathrm{M}$ 2-mercaptoethanol.

\section{STATISTICS}

Wilcoxon's rank sum test was used throughout.

\section{Experiments and results}

ABSORPTION OF OVALBUMIN

Experimental mice, previously fed ovalbumin for 14 days, and their control group were given $40 \mathrm{mg}$ ovalbumin intragastrically in $0.2 \mathrm{ml}$ saline via a Portex tube and bled from the mesenteric vein 45 minutes later. The concentrations of ovalbumin were determined using radioimmunoassay.

Ovalbumin was detected in the sera of all control mice but none was found in the sera of six out of eight mice which had previously been exposed to it (Fig. 1) $(P=0.05$ Wilcoxon rank test $)$; the two outlying values may have arisen from intubation trauma. To determine the molecular size of the detected ovalbumin the samples were pooled and passed through a Sephadex G 200 column $(3 \cdot 2 \times 40$ $\mathrm{cm})$. The fractions were concentrated by ultrafiltration to the volume of the original sample and tested for ovalbumin by RIA. Ovalbumin was detected only in the fraction containing proteins of molecular weight range $36000-54000$. No large molecular weight aggregates or polypeptides reacting with anti-ovalbumin serum on RIA were detected. Some ovalbumin is therefore absorbed with little or no change in molecular weight or antigenic determinants.

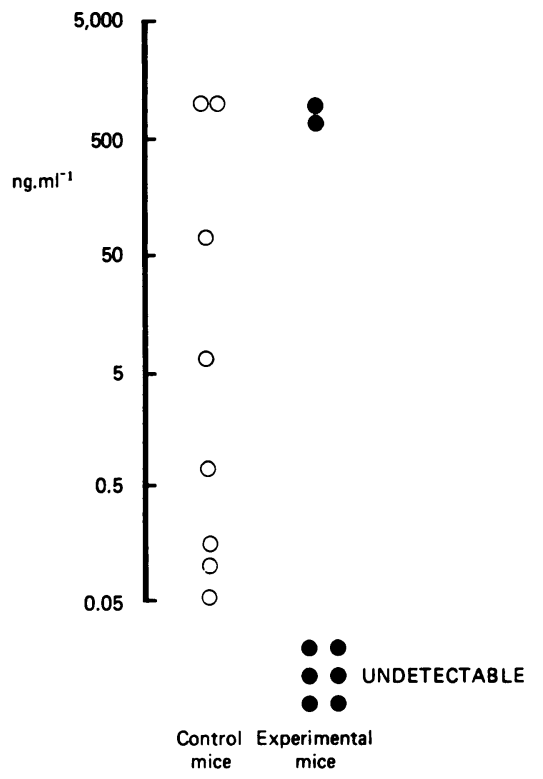

Fig. 1 Serum concentration ( $\mathrm{ng} . \mathrm{ml}^{-1}$ ) of ovalbumin after an intragastric dose. The experimental group had previously been fed ovalbumin; the control group with saline.

ELIMINATION OF OVALBUMIN FROM CIRCULATION

Since the above differences could be due to increased elimination from the circulation of the actions of antibody, complement and phagocytes-that is, 
immune elimination-the disappearance of $125 \mathrm{I}$ ovalbumin from the blood after an intravenous injection was measured.

Similar groups were injected intravenously via the tail vein with $150 \mathrm{ng}$ monomeric ${ }^{125} \mathrm{I}$-ovalbumin in $0.05 \mathrm{ml}$ phosphate buffer and bled sequentially from the retro-orbital plexus hourly for four hours using $20 \mu \mathrm{l}$ capillary tubes. The radioactivity in the blood during the four hours after intravenous injection was no different in mice which had previously been fed ovalbumin than in those previously fed saline (Fig. 2).

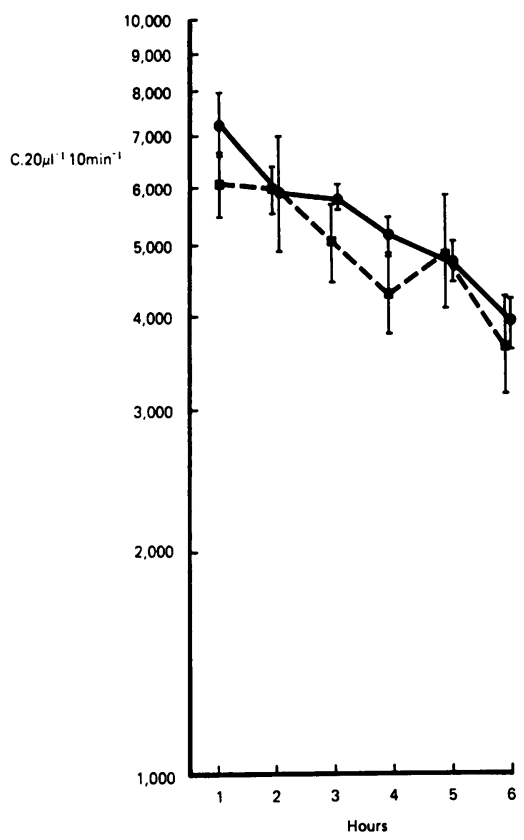

Fig. 2 The elimination of ${ }^{125}$ I-ovalbumin from the circulation after intravenous injection in mice previously fed ovalbumin (- - and in control, saline fed mice (- - - Each point is the mean from eight mice \pm 1 SEM.

The differences in serum concentration between experimental and control animals after ingestion of the antigen are therefore not due to differences of immune elimination and might be due to differences in absorption.

IMMUNE RESPONSES TO PARENTERAL

IMMUNISATION WITH OVALBUMIN

Identical groups of mice were immunised with $1 \mathrm{mg}$ ovalbumin in complete Freund's adjuvant by intraperitoneal injection 14 days after their last gavage. The animals were bled three weeks later and the antibody titre to ovalbumin measured by passive haemagglutination.
The mice not previously exposed to ovalbumin showed high titres of antibody to ovalbumin after parenteral immunisation (Fig. 3). The mice which had been fed ovalbumin showed significantly less antibody response $(P<0.01$ Wilcoxon rank test). The titres of antibody in both groups fell by only one dilution when the assay was performed in the presence of $0.1 \mathrm{M} 2-\mathrm{ME}$ and the differences were maintained.

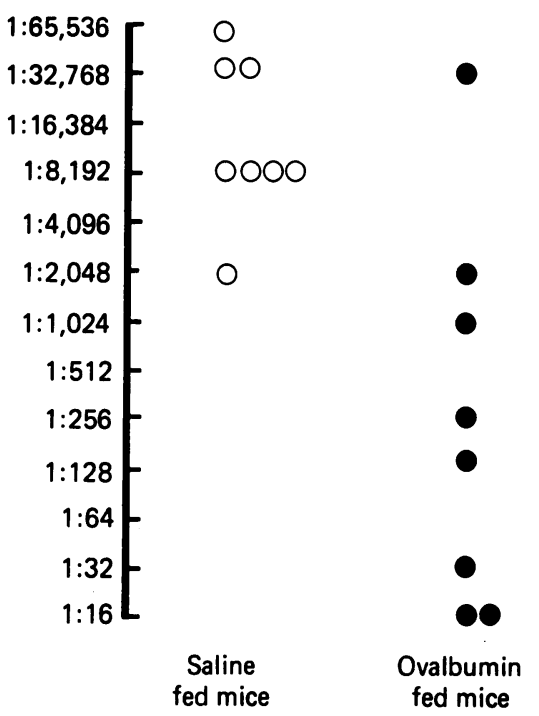

Fig. 3 Haemagglutinating anti-ovalbumin antibody response 21 days after parenteral immunisation with ovalbumin in complete Freund's adjuvant after the previous ingestion of ovalbumin or saline.

To test the specificity of this response three further groups of mice were fed saline, HSA, or ovalbumin in the same way for two weeks. After two weeks' rest all animals were immunised with $1 \mathrm{mg}$ HSA in CFA intraperitoneally and the anti-HSA antibodies assayed using a similar passive haemagglutination of HSA-coated SRBC. Mice fed saline or ovalbumin showed similar high anti-HSA antibody responses, while animals fed HSA showed reduced responses (Fig. 4) $(\mathrm{P}<0.05$ Wilcoxon rank test).

\section{Discussion}

We have shown that feeding ovalbumin to mice reduced its subsequent absorption while simultaneously inducing a state of systemic tolerance; previously, these phenomena have been reported independently. This suggests a form of split tolerance as does the work of Kagnoff (1977), who showed that 


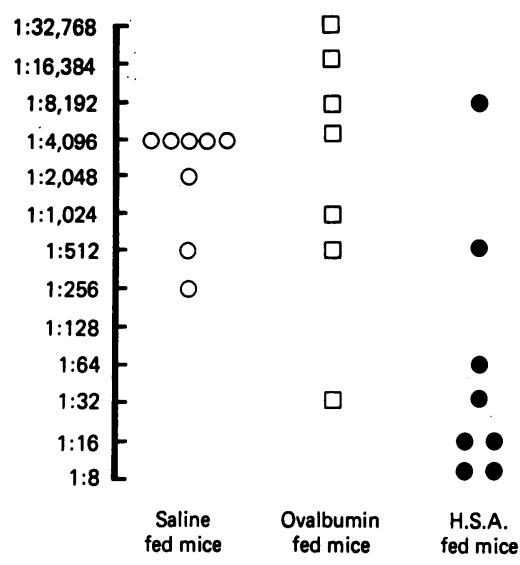

Fig. 4 Haemagglutinating anti-HSA antibody response to parenteral immunisation with HSA in complete Freund's adjuvant after tro nrevious ingestion of $H S A$ ovalbumin or saline alone

previous ingestion of sheep red blood cells increased the IgA plaque forming cells in the spleen but reduced the IgM response after subsequent parenteral immunisation.

Following the original observation in humans that bovine antigens were detectable in the blood of infants shortly after weaning but that subsequently they disappear as antibodies appear (Lippard et al., 1936), in vitro studies have shown immune exclusion after oral and parenteral immunisation (Walker et al., 1972, 1973). In vivo studies have also been reported (André et al., 1974; Walker and Bloch, 1977), though the amounts of antigen detected by André were surprisingly high and Walker's in vivo effects could have resulted from either immune exclusion or elimination. Our demonstration that oral feeding of antigen does not lead to its subsequent accelerated clearance suggests that the conventional mechanisms of immune elimination do not contribute to the altered handling of ingested antigen.

Immune exclusion may be a function of immunoglobulin, particularly secretory IgA (sIgA) (Bazin et al., 1973). Serum IgA antibodies can perform this function (Stokes et al., 1975) and it is likely that sIgA, with its intimate mucosal association (Tomasi and Bienenstock, 1968) and its innate resistance to digestion (Brown et al., 1970; Steward, 1971), functions more efficiently. Walker's in vitro experiments suggest that IgG can do it too (Walker et al., 1972).

IgA deficiency is associated with an increased incidence of antibodies to food proteins (Buckley and Dees, 1969), and with allergy, including food allergy (Ammann and Hong, 1971; Buckley, 1975). Transient IgA deficiency in the infants of atopic parents precedes the development of allergic symptoms (Taylor et al., 1973). Furthermore, allergen avoidance during the vulnerable period on these genetically predisposed children prevents the development of eczema (Matthew et al., 1977). It is possible, therefore, that lack of IgA mediated antigen exclusion may result in a damaging allergic response to such antigens absorbed across the mucosa.

There is a significant, though unusual, association of IgA deficiency with coeliac disease (Hobbs, 1971 ; Booth, 1977) which might suggest that ineffective immune exclusion of gluten or one of its constitutents induces damaging local immune reactions and produces the typical lesion in genetically vulnerable individuals. Defective antigen exclusion might also account for the immune phenomena associated with inflammatory bowel disease (Jewell and Hodgson, 1976) and the presence of circulating antifood antibodies in children with malnutrition (Chandra, 1975).

The mechanisms of orally induced tolerance are obscure. There are a number possible for tolerance to parenterally administered antigens (for review see the British Medical Bulletin, 1976) but there is evidence that at least some orally induced tolerance is different. The minute amounts of intact antigen absorbed make it likely that orally induced tolerance is of 'low zone' type and Thomas and Parrott (1974) showed that such tolerance to soluble protein antigen is T-cell dependent. However, the passive transfer to normal mice of contact sensitivity to picrylchloride and oxalazone with immune cells may involve both T or B cells (Asherson et al., 1977).

The passive transfer with serum of orally induced tolerance to SRBC has also been reported (André et al., 1975; Kagnoff, 1977) and André produced indirect evidence to suggest that it might depend upon IgA-antigen complexes. This led to the attractive hypothesis that IgA antibody-ingested antigen complexes might persist for a long time, perhaps because of lack of complement mediated opsonisation, thereby inducing tolerance. However, we have demonstrated in passive transfer experiments that IgA antibodies promote rapid elimination of antigen and increase rather than reduce the antibody response to subsequent immunisation (Swarbrick et al., 1976).

Orally induced tolerance seems to be an approc priate response to common but otherwise harmless antigens. A breakdown of this process might lead to a variety of disease states; it provides an alternative explanation to immune exclusion for the pathogenesis of allergy (Okumura and Tada, 1971) or the immune phenomena associated with coeliac disease and inflammatory bowel disease. Bazin, using an 
immunising regime similar to our own, has shown that antigen feeding can suppress subsequent IgE responses to injected antigens in rats (Bazin and Platteau, 1977) and as early as 1911 it was shown that young guinea-pigs fed maize (Wells and Osborne, 1911) oats, or egg-albumin (Wells, 1911) were resistant to anaphylactic sensitisation to these particular proteins.

Our observations suggest that the two phenomena -immune exclusion and tolerance induction-are not mutually exclusive. It is possible that they are interdependent and together would lead to the safe handling of ingested antigens.

E.T.S. was funded by the St Mark's Hospital Research Foundation. The authors wish to thank Brian Gregory and Simon Rambaran for their help with the animal handling.

\section{References}

Ammann, A. J., and Hong, R. (1971). Selective IgA deficiency: Presentation of 30 cases and a review of the literature. Medicine, 50, 223-236.

André, C., Heremans, J. F., Vaerman, J. P., and Cambiaso, C. L. (1975). A mechanism for the induction of immunological tolerance by antigen feeding: Antigen-antibody complexes. Journal of Experimental Medicine, 142, 1509 1519.

André, C., Lambert, R., Bazin, H., and Heremans, J. F. (1974). Interference of oral immunisation with the intestinal absorption of heterologous albumin. European Journal of Immunology, 4, 701-704.

Asherson, G. L., Zembala, M., Perera, M. A. C. C., Mayhew, B., and Thomas, W. R. (1977). Production of immunity and unresponsiveness in the mouse by feeding contact sensitising agents and the role of suppressor cells in the Peyer's patches, mesenteric lymph nodes and other lymphoid tissue. Cellular Immunology, 33, 145-155.

Bazin, H., André, C., and Heremans, J. F. (1973). Résponses immunologiques induites par voie orale. Annales d'Immunologie (Institut Pasteur), 124C, 253-272.

Bazin, H., and Platteau, B. (1977). Oral feeding of ovalbumin can make rats tolerant to an intraperitoneal injection of Dinitrophenylated ovalbumin and Bordetella pertussis vaccine. Biochemical Society Transactions, 5, 1571-1573.

Booth, C. C. (1977). Discussion (IgA deficiency in coeliac disease). In Immunology of the Gut, p. 256 (Ciba Foundation Symposium, 46). Elsevier Excerpta Medica: NorthHolland.

British Medical Bulletin (May 1976). Immunological tolerance. British Medical Bulletin, 32, (2).

Brown, W. R., Newcomb, R. W., and Ishizaka, K. (1970). Proteolytic degradation of exocrine and serum immunoglobulins. Journal of Clinical Investigation, 49, 1374-1380.

Buckley, R. H. (1975). Clinical and immunologic features of selective IgA deficiency. Birth Defects, 11, (1), 134-142.

Buckley, R. H., and Dees, S. C. (1969). Correlation of milk precipitins with IgA deficiency. New England Journal of Medicine, 281, 465-469.
Chandra, R. K. (1975). Food antibodies in malnutrition. Archives of Diseases in Childhood, 50, 532-534.

Chase, M. S. (1946). Inhibition of experimental drug allergy by prior feeding of the sensitizing agent. Proceedings of the Society of Experimental Biology and Medicine (N.Y.) 61, 257-259.

Hobbs, J. (1971). Immunological disturbances in the pathogenesis of malabsorption. Journal of Clinical Pathology, 24, suppl. 146-150.

Hunter, W. M., and Greenwood, F. C. I. (1962). Preparation of iodine-131 labelled human growth hormone of high specific activity. Nature, 194, 495-496.

Jewell, D. P., and Hodgson. H. J. F. (1976). Auto immune and inflammatory disease of the gastrointestinal tract. In Immunological Aspects of the Liver and Gastrointestinal Tract, pp. 208-251. Edited by A. Ferguson and R. N. M. MacSween. M.T.P. Press: Lancaster.

Kagnoff, M. F. (1977). Antigen feeding alters the immune responses of antigen sensitive cells in extra intestinal sites (Abstract). Gastroenterology, 72, 1076.

Lippard, V. W., Schloss, O. M., and Johnson, P. A. (1936). Immune reactions induced in infants by intestinal absorption of incompletely digested cow's milk protein. American Journal of Diseases of Childhood, 5, 562-574.

Matthew, D. J., Taylor, B., Norman, A. P., Turner, M. W., and Soothill, J. F. (1977). Prevention of eczema. Lancet, 1, 321-324.

Okumura, H., and Tada, T. (1971). Regulation of homocytotropic antibody formation in the rat. IV. Inhibitory effect of thymocytes on the homocytotropic antibody response. Journal of Immunology, 107, 1682-1689.

Steward, M. W. (1971). Resistance of rabbit secretory IgA to proteolysis. Biochemica et Biophysica Acta, 236, 440-449.

Stokes, C. R., Soothill, J. F., and Turner, M. W. (1975). Immune exclusion is a function of IgA. Nature, 255, 745746.

Swarbrick, E. T., Stokes, C. R., and Soothill, F. J. (1976). Elimination of antigen from the blood-a function of IgA. Gut, 18, A945.

Taylor, B., Norman, A. P., Orgel, H. A., Stokes, C. R., Turner, M. W., and Soothill, J. R. (1973). Transient IgA deficiency and pathogenesis of infantile atopy. Lancet, 2, 111-113.

Thomas, H. C., and Parrott, D. M. V. (1974). The induction of tolerance to a soluble protein antigen by oral administration. Immunology, 27, 631-639.

Tomasi, T. B., Jr., and Bienenstock, J. (1968). Secretory immunoglobulins. Advances in Immunology, 9, 2-96.

Walker, W. A., and Bloch, K. J. (1977). Evidence for immune exclusion after in vivo antigen infusion into the gastrointestinal tract. Gastroenterology, (Abstract) 72, A162-1185.

Walker, W. A., and Isselbacher, Kurt J. (1974). Uptake and transport of macromolecules by the intestine. Possible role in clinical disorders. Gastroenterology, 67, 531-550.

Walker, W. A., Isselbacher, K. J., and Bloch, K. J. (1972). Intestinal uptake of macromolecules: effect of oral immunization. Science, 177, 608-610.

Walker, W. A., Isselbacher, K. J., and Bloch, K. J. (1973). Intestinal uptake of macromolecules. 2. Effect of parenteral immunization. Journal of Immunology, 3, 221-226.

Wells, H. G., and Osborne, T. B. (1911). The biological reactions of the vegetable proteins. Journal of Infectious Diseases, 8, 66-124.

Wells, H. G. (1911). Studies on the chemistry of anaphylaxis (III). Experiments with isolated proteins, especially those of the hen's egg. Journal of Infectious Diseases, 9, 147-171. 